\title{
Scale effects in transmissivity
}

\author{
Xavier Sánchez-Vila ${ }^{\mathrm{a}, *}$, Jesús Carrera ${ }^{\mathrm{b}}$, Jorge P. Girardi ${ }^{\mathrm{c}}$ \\ ${ }^{a}$ Departament Matemàtica Aplicada III, Escola de Camins, Universitat Politècnica de Catalunya, Gran \\ Capità S/N, 08034 Barcelona, Spain

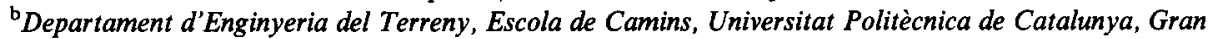 \\ Capità S/N, 08034 Barcelona, Spain \\ ${ }^{\mathrm{I}}$ Instituto de Materiales y Suelos, Facultad de Ingenieria, Universidad Nacional de San Juan, Urquita 35-N, \\ 5400 San Juan, Argentina
}

Received 9 May 1994; revision accepted 20 September 1994

\begin{abstract}
Heterogeneity accounts for several paradoxes in groundwater flow and solute transport. One of the most striking observations is the emergence of scale effects in transmissivity, that is, the increase in effective transmissivity (or hydraulic conductivity, for that matter) with increasing scale of observation. Traditional stochastic approaches, where transmissivity is treated as a multilog-normal random function, lead to a large-scale effective transmissivity equal to the geometric average of local measurements.

We present several field cases in which large-scale transmissivities are indeed larger than the geometric average of local tests. This suggests that the assumption of multilog-normality may not be valid in many cases, even if point $T$ values display a $\log$-normal distribution. We conjecture that scale dependence of $T$ may, in part, be a consequence of high $T$ zones being better connected than average or low $T$ zones, a feature which may occur in many geological environments, but which is not consistent with multinormal $\log -T$ fields. We go on to generate a suite of $\log -T$ fields with a normal distribution for point values but non-multinormal spatial correlation. In all our fields, high $T$ zones show longer correlations than average of low $T$ zones. By simulating flow through these synthetic fields under simple boundary conditions, and estimating their effective transmissivity values, we conclude that these types of departures from the multilog-normality assumption lead consistently to scale effects.
\end{abstract}

\section{Introduction}

Heterogeneity is a fundamental characteristic of nature, which is present in most variables representing natural phenomena. Heterogeneity appears at any scale of

\footnotetext{
* Corresponding author.
} 
observation, from the local (or laboratory scale) to the original (macrostructures), in the notation of Dagan (1986). When not taken into account, inconsistencies arise between field observations and model predictions. It is well known that the traditional approach to solute transport simulation fails to reproduce phenomena such as scale effects in dispersivity (Lallemand-Barres and Peaudecerf, 1978). The scale effect in dispersivity is the most dramatic and best documented anomaly of solute transport, but it is not the only one. Anomalies can be found in breakthrough and solute distribution curves, in porosites and dispersivities derived from convergent flow tracer tests, in dispersion upstream of the source, etc. (Carrera, 1993; Sánchez-Vila et al., 1992).

We focus here on another anomaly, the scale effect in transmissivity $(T)$ or hydraulic conductivity $(K)$. Matheron (1967) proved, under rather general conditions, that large-scale effective transmissivity equals the geometric average of local values. Yet, it has been observed that, in real situations, large-scale effective values of transmissivity often exceed the geometric average of small-scale transmissivities. The fact that this effect is rarely, if ever, mentioned in the hydrologic literature can be attributed to several causes. On one hand, hydrogeologists can seldom estimate flow rates and head gradients accurately in real aquifers, so they do not bother to derive effective transmissivities. On the other hand, when such data are available, hydrogeologists would rather simulate heterogeneity explicitly, so that effective values become uninteresting and irrelevant. Moreover, this effect is more

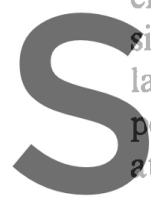
significant in low-trat large. Since hydrogeol ermeability enviroments, tention to date.

It seems clear that scale dependence of transmissivity and hydraulic conductivity is

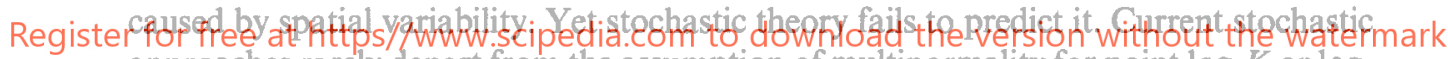
approaches rarely depart from the assumption of multinormality for point log- $K$ or $\log$ $T$ values. It is indeed a simple hypothesis, but it lacks empirical or theoretical support. In fact, we contend that multinormality of $\log -T$ is a poor hypothesis for representing most real aquifers. One of the properties of the multinormal distribution is that the average size of regions with $\log -T$ values above a certain percentile decays quickly with the percentile and it does so in the same manner for high $\log -T \mathrm{~s}$ as for low $\log -T \mathrm{~s}$. Instead, we conjecture that in most situations high $T$ values are better connected than low $T$ values. Here, connectivity implies a number of different things: geologically, it means that we can find some paths that group high $T$ values, possibly superimposed on a heterogeneous matrix of smaller $T$ values; physically, it means that high $T$ values remain correlated over larger distances than low $T$ values; statistically, it means that correlation depends not only on distance, but also on the value of $T ; \ldots$ This work is aimed at showing that the conjecture about long connectivities of high point $T$ values is well grounded and explains scale effects.

We start by reviewing the stochastic theory related to effective parameters. Then, we show some real cases which favor the idea of $T$ increasing with scale, including some that might seem to favor the opposite. Possible explanations are sought for the latter cases. Later, we explain a geologic conjecture to give some physical insight into 
scale effects in $T$. Next, several synthetic fields, generated by different methods are used to test our basic conjecture and some results of simulated flow are displayed. Finally, the conclusions of this work are stated.

\section{Effective hydraulic conductivity: review}

We consider it important to start by reviewing theoretical findings for effective hydraulic conductivity in heterogeneous media. We focus on the limitations and hypotheses under which they are valid. Our starting point is Darcy's law

$$
\boldsymbol{q}(\boldsymbol{x})=-K(\boldsymbol{x}) \nabla h(\boldsymbol{x})
$$

where $\boldsymbol{q}(\boldsymbol{x})$ is Darcy's flux, $K(\boldsymbol{x})$ is hydraulic conductivity and $h(\boldsymbol{x})$ is piezometric head. This equation is valid and applicable at the local scale, the one in which the value of $K$ was obtained. Although $K$ can be treated as a tensor, we consider that at the local scale it can be represented by a scalar.

A natural question that arises when studying an aquifer is the possibility of applying a similar type of equation at the regional scale. What we really want to do is to use an equation that integrates the local Darcy fluxes and piezometric heads for a given region under certain boundary conditions, and looks like

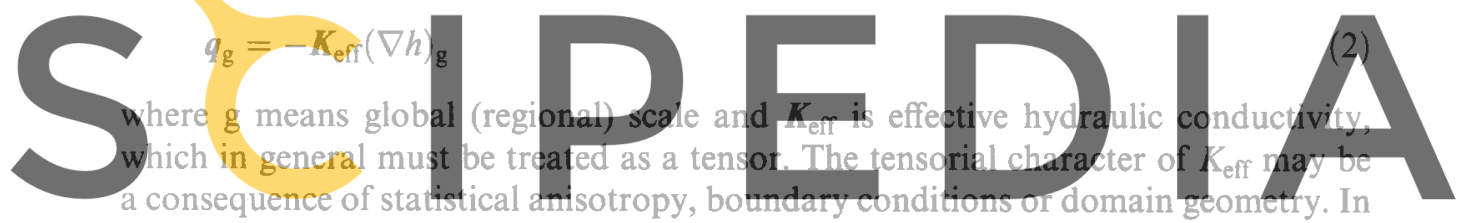

Eg. (2) we should use an equivalent permeability instead of an effective one, as we are

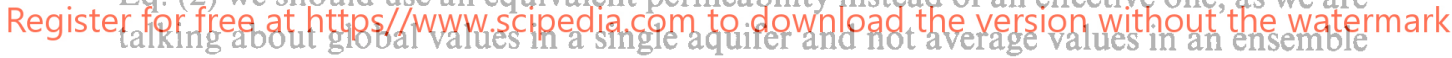

of realizations. The two concepts, equivalent and effective transmissivity, become interchangeable for stationary random functions over large domains (compared with the integral scale), in which case ergodicity holds.

Effective hydraulic conductivity in heterogeneous media has been the subject of several studies since the sixties. Matheron (1967), who quoted earlier work by Schvidler (1964), obtained bounds for $K_{\text {eff }}$ by using some energy considerations. He found that $K_{\text {eff }}$ was bounded by the arithmetic $\left(K_{\mathrm{A}}\right)$ and the harmonic mean $\left(K_{\mathrm{H}}\right)$ of the point values

$$
K_{\mathrm{H}} \leq K_{\mathrm{eff}} \leq K_{\mathrm{A}}
$$

Matheron (1967) also demonstrated that in a two-dimensional (2-D) infinite domain $K_{\text {eff }}$ was equal to the geometric mean $\left(K_{\mathrm{G}}\right)$ of the point $K$ values, provided that $K /\langle K\rangle$ and $H /\langle H\rangle$ have the same 'spatial law', which should be invariant by rotation ( $H=K^{-1}$ being resistivity and $\langle\cdot\rangle$ standing for the expected value). By 'spatial law', Matheron means the ensemble of all functional moments, which fully characterize the random function. These conditions are met, for example, when $K$ is a multilog-normal stationary random function with isotropic correlation. 
The latter result $\left(K_{\mathrm{eff}}=K_{\mathrm{G}}\right)$ in a 2-D infinite domain was also found by Dagan (1982) using a self-consistent approach. Gutjahr et al. (1978) used the small perturbation approach to derive effective parameters for flow in a medium of dimensionality $n$. Their findings can be summarized in a simple formula

$$
K_{\mathrm{eff}}=K_{\mathrm{G}}\left[1+\left(\frac{1}{2}-\frac{1}{n}\right) \sigma_{Y}^{2}\right]
$$

where $\sigma_{Y}^{2}$ is the variance of $\ln -K$. Gelhar and Axness (1983) extended Eq. (4) to media with anisotropic correlation structure. These authors also conjectured that Eq. (4) could be extrapolated to large $\sigma_{Y}^{2}$ and suggested that it is possible to consider Eq. (4) as the first terms in the expansion of an exponential, so that the equation becomes

$$
K_{\text {eff }}=K_{\mathrm{G}} \exp \left[\left(\frac{1}{2}-\frac{1}{n}\right) \sigma_{Y}^{2}\right]
$$

The same conjecture had been made for a totally different problem by Landau and Lifshitz (1960). Dagan (1993) derived another small perturbation expression for $K_{\mathrm{eff}}$ including terms up to order $\sigma_{Y}^{4}$ and found it in agreement with the expansion of Eq. (5).

Other authors have made contributions to the study of $K_{\text {eff. }}$ Kitanidis (1990) studied gradually varying mean flow. Loaiciga et al. (1993) considered the presence of trends in mean $\mathbb{K}$. Naff (1991) analyzed radial convergent flow. Neuman and Orr (1993) carried out a very comprehensive study where, among many other things, they analyzed the existence

ccount different types aleologos and Neuma

After Smith and Freeze (1979), other authors have used numerical simulations; for

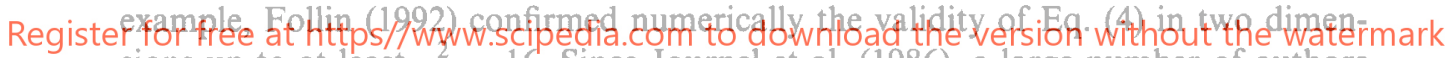
sions up to at least $\sigma_{Y}^{2}=16$. Since Journel et al. (1986), a large number of authors have used a combined analytical-numerical method to estimate effective parameters based on a power-averaging formula. Gómez-Hernández and Gorelick (1989) used this type of formula to analyse a synthetic case. Ababou and Wood (1990) found the power-averaged value as a function of the different means of $K$ : geometric, arithmetic and harmonic. Desbarats (1992) analyzed the validity of the formula for high variances.

Log-normality of the point $K$ values (or $T$ for that matter) has been traditionally accepted by the scientific community since works by Law (1944) and Davis (1969). This led in a natural way to acceptance of multilog-normality whenever $K$ was treated as a regionalized variable. One of the nice properties of normal functions is that they are fully characterized by their expected value and covariance function. Moreover, the correlation structure is usually given in terms of a single covariance function, so that high $K$ values are correlated among themselves in exactly the same way as low ones. One property of this type of structure is that the correlation distance for values above a given threshold decays as the threshold increases. We want to stress that multinormality is just a working hypothesis made only because it simplifies enormously the work with random variables, and that it has not been (and probably cannot be) proved. 
The idea of using distributions other than normal for the point values pdf has been addressed by different authors. Desbarats (1987) and Gómez-Hernández (1991) studied the problem of effective parameters in bimodal (sand-shale) aquifers. It is widely accepted that in these cases $K_{\text {eff }}$, whenever it can be defined, is not necessarily given by Eq. (4).

Our main objective in this paper is to show that relaxing the hypothesis of multi$\log$-normality will lead to $T_{\text {eff }}$ values which again do not agree with $T_{\mathrm{G}}$ in 2-D domains, even when point values display a log-normal distribution. For this purpose, we generate, in different ways, a number of fields all of which have in common one feature: high local values of the variable display better connectivity patterns than low ones. After performing flow simulations in these fields, we find than in every case a value for $T_{\text {eff }}$ higher than $T_{\mathrm{G}}$ is obtained. We do not want to give the wrong impression that non-multilog-normality of the random variable $T$ is the only cause of scale effects in transmissivity. Newman (1994) considers that scale effects may appear owing to the non-stationarity of $T$ (the spatial correlation being fractal-type). In real aquifers, boundaries could also account for differences between $T_{\text {eff }}$ and $T_{\mathrm{G}}$ (Paleologos and Neuman, 1995). Even sampling techniques may have some effect. In this paper we want to concentrate only on the importance of the relaxation of the multilog-normality assumption, disregarding other possible causes (as they have been studied elsewhere). This is why we keep the log-normality for the monavariate pdf of the $T$ values in all the simulations

As a motivating $p$ scale effects in transinit multilog-normality
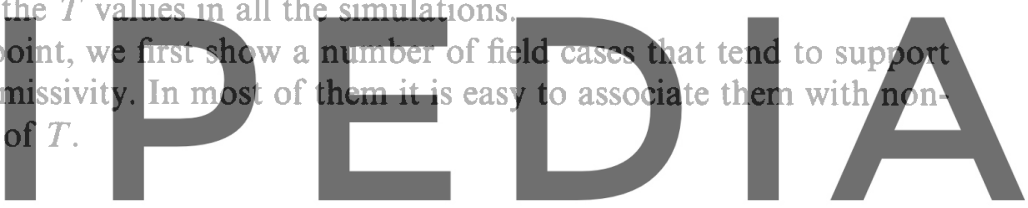

Registerforifree sutphttps//www.scipedia.com to download the version without the watermark

We point out several field cases reported in the literature which support the idea of scale effects in either $T$ or $K$. We should remember here that our goal is not to provide an exhaustive review, but just to show that scale effects appear in many different types of aquifer and that it has been observed by some authors.

\subsection{Example 1: field case - Chalk River}

The Chalk River Nuclear Laboratories are located $200 \mathrm{~km}$ northwest of Ottawa in Ontario, Canada. From a geological point of view, the zone is very complex, with a main structure of folded monzonitic gneisses, limited at the top and bottom by paragneisses. Several inclusions of metagabbros, diagabbros and pegmatites can also be found. A large number of faults and fractured zones intersect the area of study. Five big discontinuities have been detected. One of them, termed Fracture number 1 , seems to be present in all the modelled area and to be subhorizontal. Additional information about the site, including sampling and other data available are given in Raven et al. (1985). 
Regarding Fracture number 1, transmissivity data coming from slug and injection tests were available in nine boreholes drilled in the area. These data are considered as 'point values'; that means, they represent an average value over a small area surrounding the borehole (local scale). The geometric mean of the values was $T_{\mathrm{G}}=2.3 \times 10^{-6} \mathrm{~m}^{2} \mathrm{~s}^{-1}$. A long-term pump test was performed independently. Drawdowns were recorded in about 40 intervals, some of which intersected the fractures. This test was interpreted using a quasi-three-dimensional inverse modelling approach (Carrera and Heredia, 1988; Carrera et al., 1990). Best fitting between observed and computed data was obtained for an estimated $T$ value in Fracture $1, T_{\text {est }}=$ $4.6 \times 10^{-5} \mathrm{~m}^{2} \mathrm{~s}^{-1}$, which is 20 times higher than $T_{\mathrm{G}}$. This showed a large increase when going from the local scale (point values) to the regional scale. The fact that 40 observation points were fitted with a relatively simple model, and that the model predicted successfully subsequent tests, suggest that such a large effective transmissivity is not a numerical artefact.

\subsection{Example 2: summary of data on crystalline rocks}

Clauser (1992) presents a compilation of permeability data on crystalline rocks from 67 locations world-wide, drawn from 48 independent references. Measurements were carried out at different scales, ranging from laboratory dal'a to packer tests, Lugeon tests and calibration of models, among others. Fig. 1 is a synopsis of all the data collected by Clauser and clearly shows an increase in avergge porneability of around three orders of magnitude from the laboratory to permeabilities tend ffect). The increase regional scale.

Register for free at https//www.scipedia.com to download the version without the watermark 3.3. Example 3: Dakota aquifer

One of the most spectacular field cases is the one reported by Bredehoeft et al. (1983), as quoted from Neuzil (1986), concerning the Pierre Shale formation, which acts as a semiconfining layer of the Dakota aquifer. The authors found that, at the regional scale, these shales were around a thousand times more permeable than what could be derived from laboratory and field tests (local scale).

\subsection{Example 4: other sources of data}

The three previous examples can lead to the wrong impression that scale effects in $K$ are a phenomenon characteristic of flow in fractured media. This is not the case; the same effect does appear in porous media, but it is not as dramatic as in the above examples. Moreover, data are rarely available at different measurement supports, or simply heads and/or yields are not well known. Anyway, some authors have found similar effects in different types of porous media, disregarding whether the point distribution function of $\log -K$ is binary (G. Teutsch, personal communication, 1992) or Gaussian (Bradbury and Muldoon, 1990). In particular, Bradbury and 


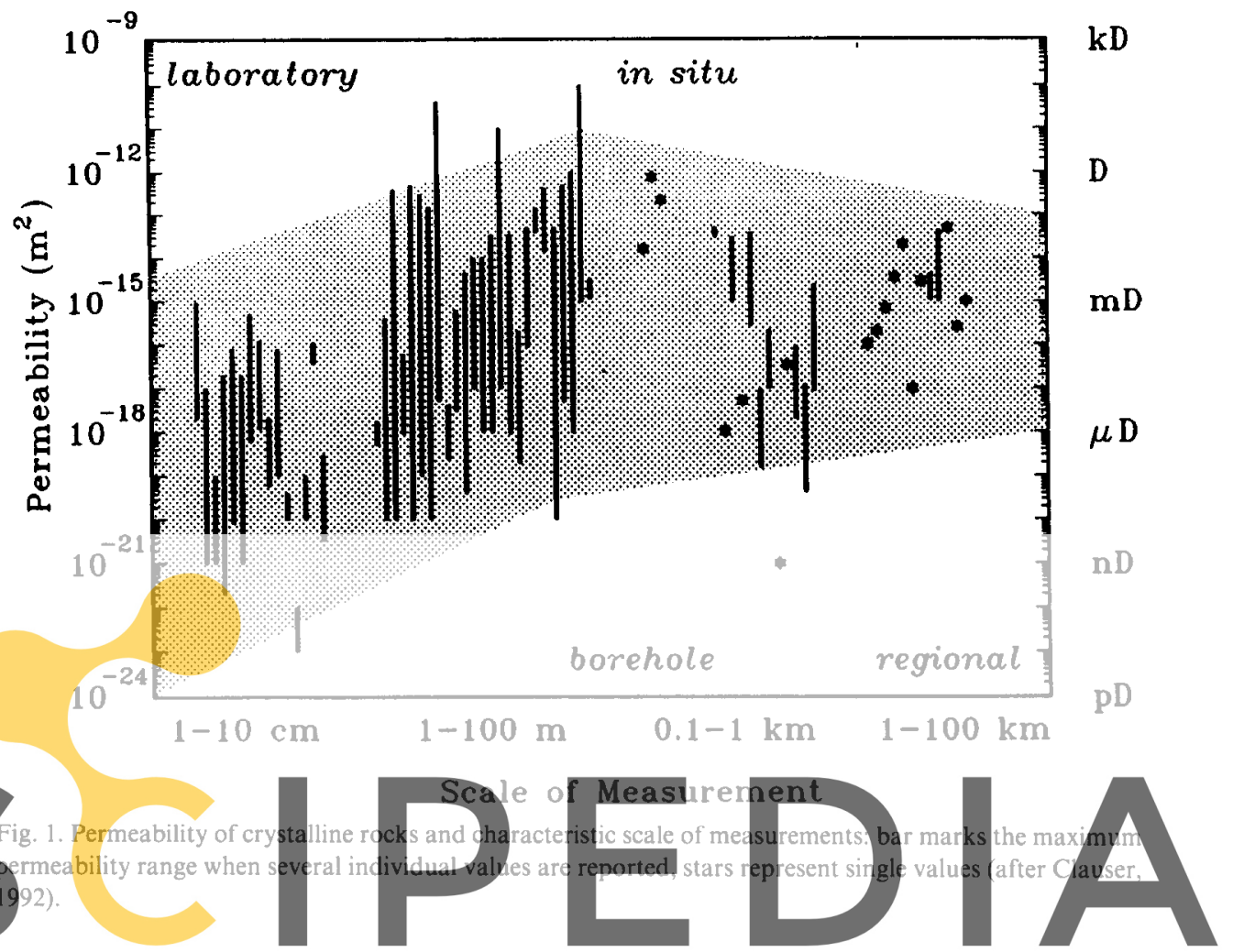

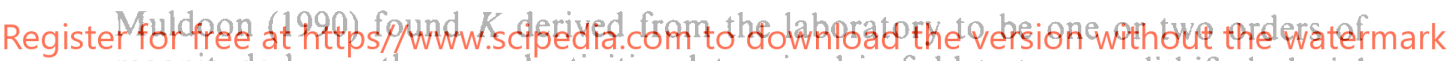
magnitude lower than conductivities determincd in field tests on unlithified glacial and fluvial materials in different locations in Wisconsin (USA).

However, when analysing convergent flow (actually, flow towards mines), $T$ values appear to behave in a different manner. When increasing the distance from the pumping point, the fitted transmissivity value tends either to stabilize (for the Stripa site, Guerin and Billaux, 1993) or even to decrease (Grimsel site, Cacas et al., 1990). There are two possible explanations for that. First, it is not clear at this point how equivalent $T$ values should vary with distance from the well point. Naff (1991) shows analytically, via perturbation expansion, that the effective $K$ value in porous media under convergent flow will decrease with increasing distance from the pumping well, more in agreement with the data from the Grimsel and Stripa sites, although other authors tend to disagree with his findings. Similarly, Cacas et al. (1990) developed a fracture network model and found that equivalent hydraulic conductivity is a decreasing function of scale in fractured media under convergent flow conditions for short to intermediate distances. Second, these measurements have been taken in galleries, thus possibly they are affected by the decompression of the rock surrounding the opening. This would be manifest in an increase of local $T$ values for short distances, but would not have an important effect a little further away (undisturbed 
rock). In any case, it is clear that we need more theoretical developments before arriving at any conclusions about scale effects in $T$ under convergent flow conditions.

\section{Geological conjecture}

The increase in effective transmissivity with the scale of observation is often attributed to the appearance of high $T$ zones as the flow domain grows. Indeed, the probability of including such zones within the flow domain increases with its size, especially if a fractal structure is assumed for the $T$ field. However, we believe that, disregarding site-specific effects, scale effects can usually be associated with the presence of high transmissivity zones which are better connected than low ones. At this point, it is important to remember that multigaussian stochastic models are incapable of representing such a difference in the connectivity pattern. In this section we argue that these differences in connectivity should be present in most real sites, both in fractured and porous media.

An exhaustive analysis of geological environments is well beyond the scope of this paper. Therefore, instead of listing types of rocks, we will restrict ourselves to single fractures, fracture networks and porous media.

High transmissivity values in single fractures are caused by zones of large aperture. Their connection is supported by direct observations of water outflow in fracture traces and by indirect decluction from tracer and hydraulic tests (Bourke, Neretnieks, 1987).

nowadays. Channelling can be caused by dissolution of more often, by shear strains. These should

bourhood of irregularities. In fact, shear strains should lead not only to channelling,

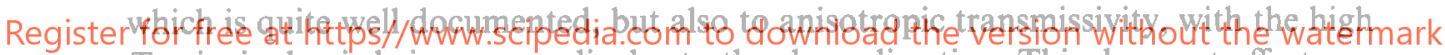
$T$ principal axis being perpendicular to the shear direction. This does not affect our contention of high connectivity of large transmissivities in fracture planes.

When moving to the scale of fractured media, the very concept of hydraulic conductivity rests on the assumption that one can define a block size above which water flow can be adequately described by Darcy's law. While this assumption has been explicitly stated by a few researchers (Neuman, 1987; Follin, 1992), it has been implicitly made by most. It is based on the fact that, when testing boreholes, the vast majority of intervals behave according to standard well hydraulics formulations, which suggests the appropriateness of their basis (i.e. Darcy's law). Accepting this treatment for fractured media, connectivity of high $K$ zones is derived from the fact that they are caused by fractures, which naturally tend to extend over long distances.

The discussion is more complex for porous media. Owing to the reasons presented in the introduction, scale effects in porous media are rarely reported. Still, we expect to find largely connected high $T$ zones more as the rule rather than as the exception. Fluvial deposits are the easiest to discuss. Fogg (1990) views fluvial sand-body architecture as a low-permeability matrix in which a highly conductive channel sand network is embedded. Low $K$ values are expected to have a short correlation length (corresponding to the matrix), while high $K$ values display a much larger one 


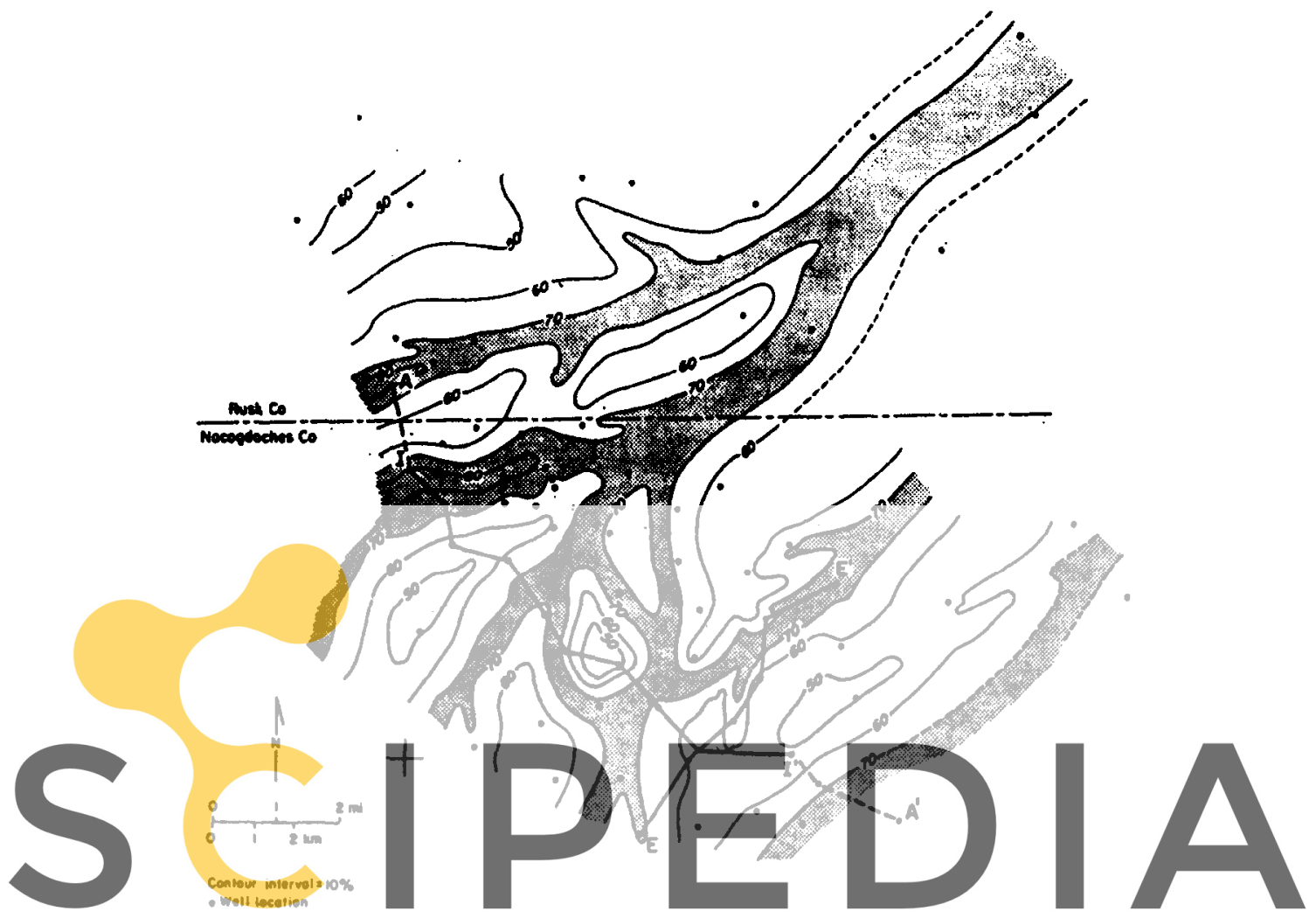

Fig. 2. Sand content map of a part of the Wilcox group, Trawick areg, east Texas. Notice that the shaded

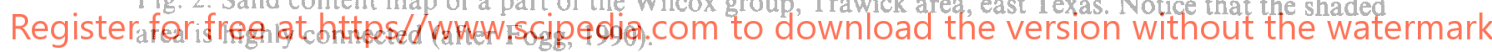

(corresponding to the embedded chanel network). An example is given in Fig. 2 , where high transmissivity zones (corresponding to large sand contents) display a totally different pattern (more elongated and interconnected) than low transmissivity zones. In general, one should expect fluvial deposition systems to lead to high $K$ along palaeo-channels which, by their very nature, should be well connected.

In summary, both fractured and porous media should be expected to display significant connectivity of high $K$ zones.

\section{Simulations}

We present a number of numerical simulations intended to show that deviations from multilog-normality in $T$ can lead to scale effects. The methodology comprises two steps.

(1) Generate a 2-D transmissivity field. We consider a rectangular domain and discretize it into a series of small square blocks. We then assign a $T$ value to 
each one of these squares and consider them as point values, so that the size of these small blocks is considered representative of the local scale. Two characteristics of the $T$ values are, first, that point values follow a $\log$-normal distribution, and second, that we can arrange these values throughout the domain to follow a certain connectivity pattern. As we are interested in effective values (regional scale), but discretization is on the size corresponding to the local scale, we need very refined meshes. This introduces some additional requirements to the computer code used to solve the flow equation, as indicated in point (2).

(2) Solve the steady-state flow equation under very simple boundary conditions like the ones shown in Fig. 3. When applied to a heterogeneous field, we get a mean gradient which is constant and parallel to the $X$-coordinate axis. Under such conditions, the effective transmissivity $T_{\text {eff }}=-Q_{\mathrm{T}} \times L_{x} / \Delta h$, where $Q_{\mathrm{T}}$ is the total flux per unit width into (and out of) the domain and $L_{x}$ is its length. Flow is solved with a finite element computer code, FAITH (Sánchez-Vila et al., 1993), especially designed to solve the groundwater flow and solute transport equations in heterogeneous media with large meshes.

The first step is carried out for a number of fields where $T$ values are distributed according to different types of correlation pattern. The second one is then applied to each one of the generated fields. In the following we present a few examples. Simulations are far from ex tensive. Our main point is that by simply relaxing the condition of multinormality, we are able to find a number of transinissivity patterns that display scale effects.

Field number 1
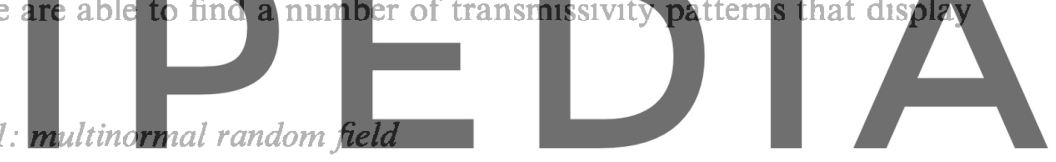

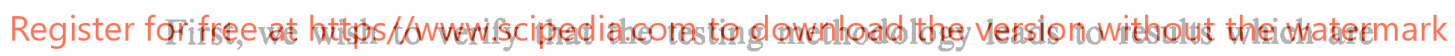
coherent with the theory when multilog-normality is retained. We simulate a $T$ field, assuming $\bar{Y}=$ in $T$ is a stationary random function with isotropic correlation structure. Therefore, we expect to obtain $T_{\text {eff }}=T_{\mathrm{G}}$. Our synthetic domain has a size of $3000 \times 3000$ units of length and it is discretized into $300 \times 300$ equal-size square elements. We generate the 90000 point $Y$ values with program GCOSIM3D

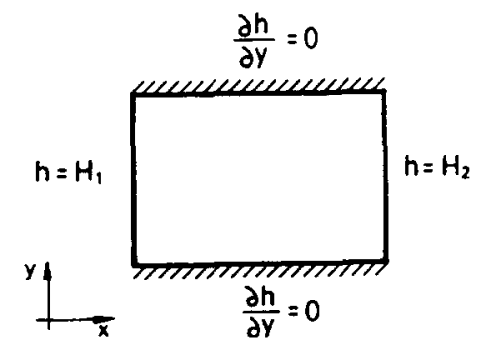

Fig. 3. Boundary conditions applied in rectangular domains to compute effective transmissivity in a heterogeneous $T$ field. 
(Gómez-Hernández and Journel, 1993), which uses sequential simulation. The correlation model is exponential and isotropic, of the type $C_{Y}(r)=\sigma_{Y}^{2} \exp (-r / \lambda), r$ being the euclidean distance, with $\lambda=100$ units length and $\sigma_{Y}^{2}=0.80$. Fig 4 shows the univariate pdf for variable $Y$. Fig. 5 reproduces the normalized variogram, compared with the initial variogram input in GCOSIM3D. The field generated has a sample mean $\langle Y\rangle=2.01$ and a sample variance $\sigma_{Y}^{2}=0.809$. Reproduction of the input conditions can be considered acceptable, except that the range of the sample variogram is clearly shorter than the input model, which is a characteristic of the sequential simulation methodology when the input model for the variogram is exponential. Anyway, the difference in the ranges between theoretical and sample variograms is not relevant in our later analysis. The final field can be seen in Fig. 6, where it is represented in a four tonality grey plot, black being the most conductive quartile and white the least conductive quartile. When flow is solved with the boundary conditions shown in Fig. 3, an effective value $T_{\text {eff }}=7.466$ is obtained. This value is virtually identical to the geometric mean, $T_{\mathrm{G}}=7.469$.

\subsection{Field number 2}

The next task consists of generating a new field displaying a different connectivity pattern. The starting point is field number 1 (exponential isotropic correlation structure, with $I=100$ ). We generate a realization of a binary field, with $300 \times 300$

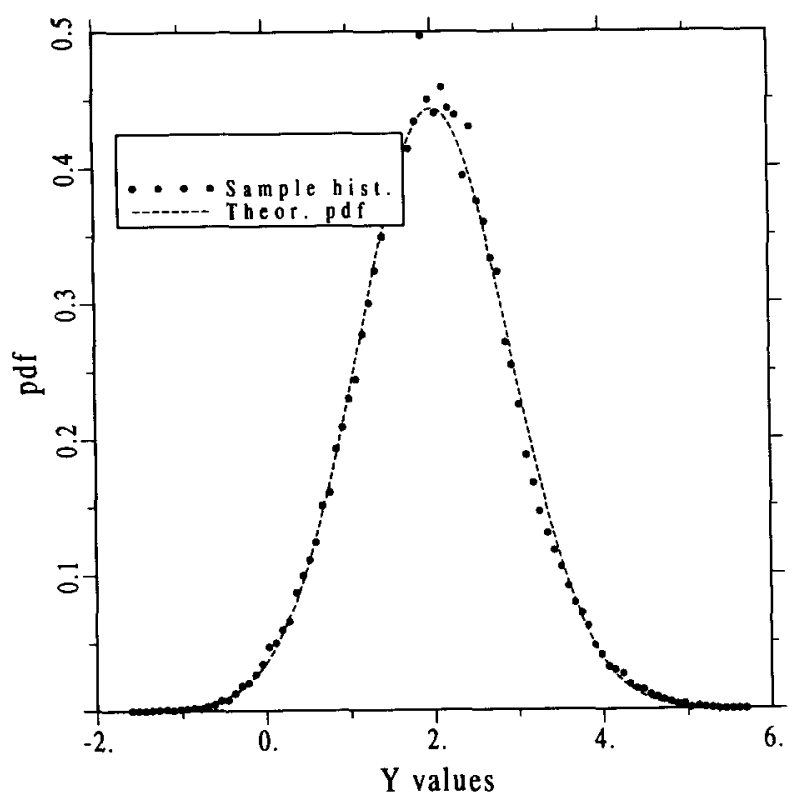

Fig. 4. Histogram corresponding to synthetic field number 1. 


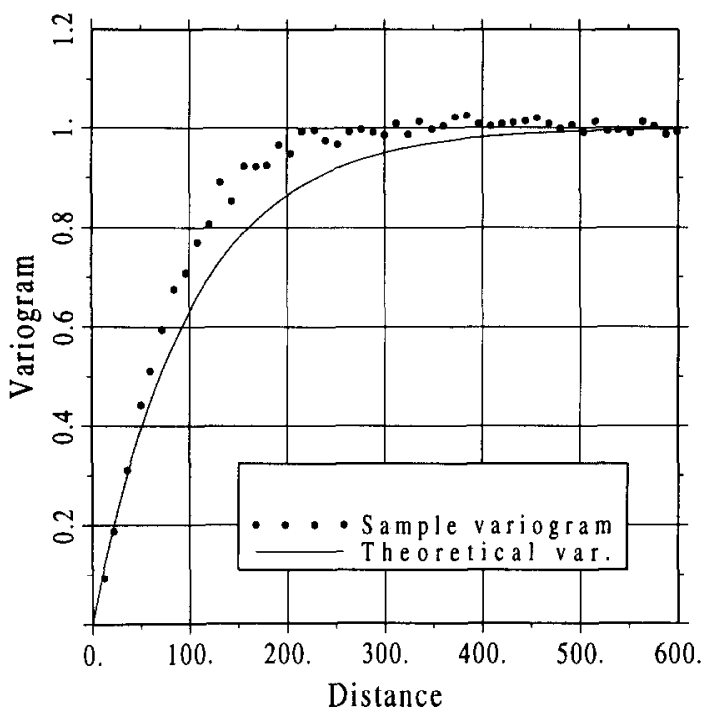

Fig. 5. Normalized variogram corresponding to synthetic field number 1 .

square elements, defined by the indicator function

$$
I(\boldsymbol{x})= \begin{cases}1 & \text { if } T(\boldsymbol{x})>T_{\text {ref }} \\ 0 & \text { if } T(\boldsymbol{x})<T_{\text {ref }}\end{cases}
$$

where $T_{\text {ref }}$ is the value corresponding to percentile 0.75 . The indicator variogram function used is also exponentially isotropic, but with a larger correlation distance with respect to field number $1 ; \lambda$ now is equal to 1500 units length. This second field is generated with program ISIM3D (Gómez-Hernández and Srivastava, 1990). The locations where $I=1$, which are affected by this larger $\lambda$, are assigned a very high random $T$ value. We now create a new $T$ field by taking the value from the indicator field at locations where $I=1$ or the value from field number 1 when $I=0$. The Gaussian distribution of $Y$ is later imposed with the help of program CLASSIFY (developed by J. J. Gómez-Hernández), which basically adapts the pdf of the $T$ values to any predetermined shape, by simply drawing random numbers within each class of values according to the cumulative distribution function predefined. The final field can be seen in Fig. 7, now in a five grey tonality plot for the quantiles, again from black (high $T$ values) to white (low $T$ values).

The new field has a mean $\langle Y\rangle=2.11$ and a variance $\sigma_{Y}^{2}=0.958$. Fig. 8 is a plot of the indicator variograms for quartiles $0.25,0.50$, and 0.75 (indicators 1,2 , and 3 in the figure). This plot shows a very different type of correlation with respect to the original one, with an increasing correlation distance for the higher transmissivity values; in this case, the ratio between the ranges corresponding to indicators 1 and 3 is approximately 4. The same trend is seen in Fig. 7; the correlation between black points (high $T$ values, drawn from the indicator field) is very different from the one between whites 


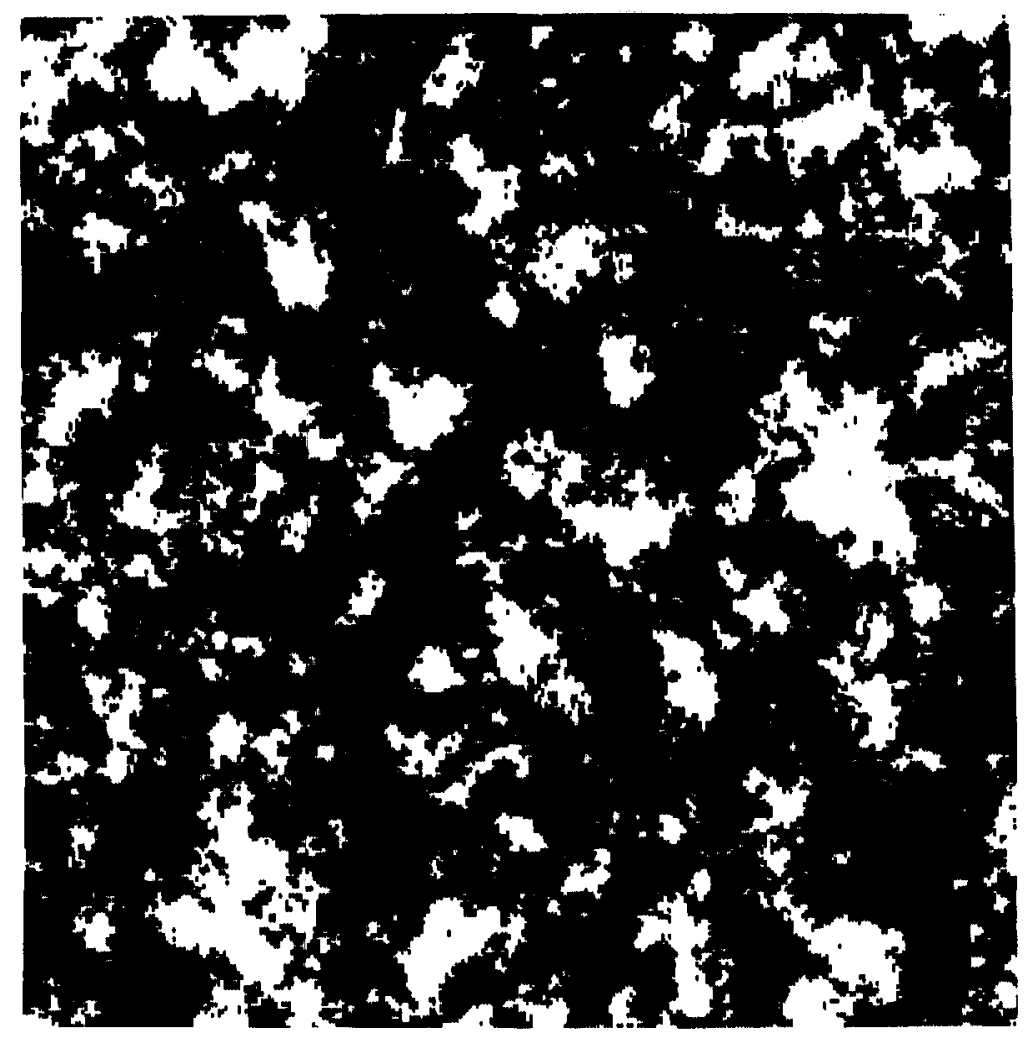

Fig. 6. Grey plot for synthetic field number 1 .

(low values, drawn from field number 1). Simulation of flow in this field leads to an effective value $T_{\text {eff }}=9.297$, which is around $13 \%$ higher than the corresponding geometric mean $\left(T_{\mathrm{G}}=8.265\right)$.

This result appears to contradict Matheron's (1967) conclusions about $T_{\text {eff }}$ being equal to $T_{\mathrm{G}}$ in 2-D flow domains. Actually, this is not the case. One of the hypotheses in Matheron's derivation was that $T /\langle T\rangle$ and $T^{-1} /\left\langle T^{-1}\right\rangle$ had the same 'spatial law' (see Section 2), meaning that all functional moments of both variables should coincide. In our example, it is clear that the indicator variogram corresponding to percentile 0.75 displays an integral distance longer (actually, four times longer) for $T$ than for $T^{-1}$ (notice that the $p$ quantile of $T$ is identical to the $1-p$ quantile of $T^{-1}$ ). That is, 'spatial laws' of $T$ and $T^{-1}$ are different, so that one of the main hypotheses in Matheron's derivation is not kept. There is no reason why $T_{\text {eff }}$ and $T_{\mathrm{G}}$ should be equal in such a case.

Certainly, the difference is not very big, possibly owing to the quite small variance considered (around 0.8 for $\sigma_{\ln T}^{2}$ ). Another possible reason stems from the fact that the contrast between ranges for the different indicators is only 4; a larger ratio would probably result in a larger effect. To evaluate the effect of the variance, we repeat this 


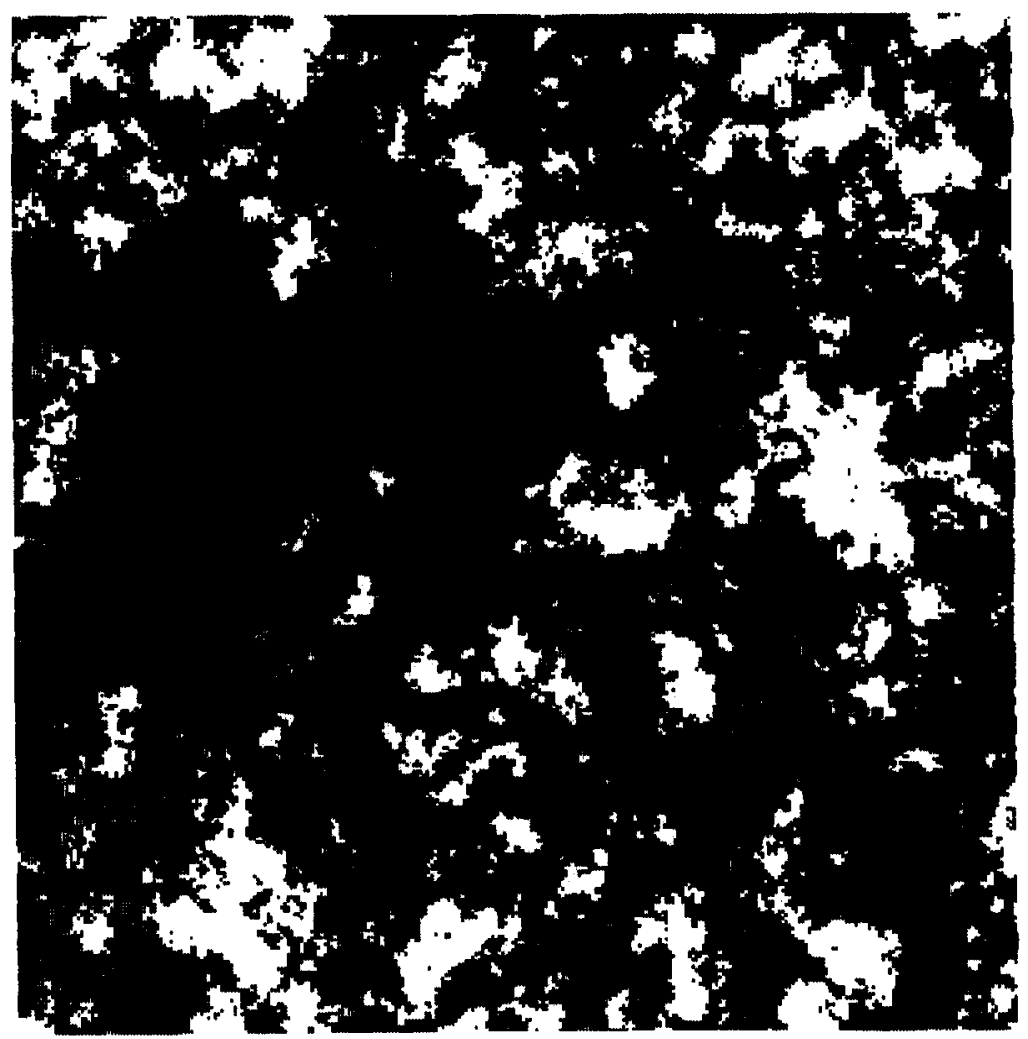

Fig. 7. Grey plot for synthetic field number 2 .

example, keeping the same structure, but changing the values so that the mean is kept constant $(\langle Y\rangle=2.112)$, but the variance is increased by a factor of 9 (with a final value $\left.\sigma_{Y}^{2}=8.628\right)$. In this case we find $T_{\text {eff }}=13.90,86 \%$ higher than $T_{\mathrm{G}}$. We see the importance of increasing the variance. This may hint at why scale effects in $T$ are more frequently observed in fractured media, where variances are larger, than in porous media.

\subsection{Field number 3}

In this third example, we check the effect of another type of correlation structure. The starting point is again field number 1 , where we superimpose a number of randomly located high transmissivity zones. The original field is again $300 \times 300$ elements and the new zones are $15 \times 1$ elements each. The same number of zones in the horizontal and the vertical directions are generated, thus keeping invariance by a $90^{\circ}$ rotation (another of Matheron's basic hypotheses). A total of $23 \%$ of the point $T$ values correspond to these high conductivity elements. Superposition is performed by dropping the original value and substituting it by the new (high) one whenever the 


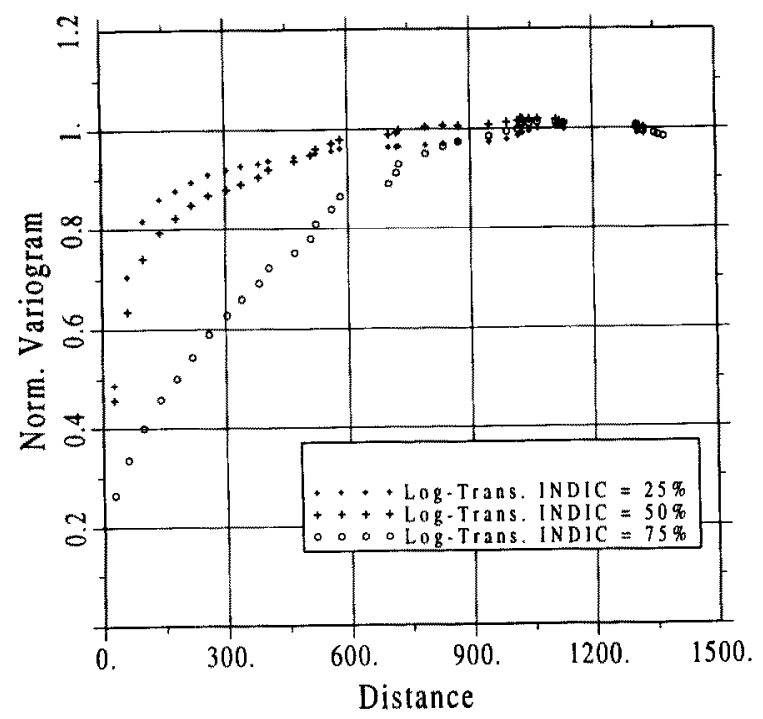

Fig. 8. Normalized indicator variograms for percentiles $0.25,0.50$ and 0.75 corresponding to field number 2 .

location corresponds to any of the high transmissivity elements. We again used CLASSIFY to force a $\log$-normal pdf of the point $T$ values. The final field can be seen in Fig. 9. It is easy to recognize the large $T$ values as thin lines of equal length, randomly distributed. Multilog-normality is clearly not retained. Again, regarding Matheron's derivation, the correlation structure of high $T$ values is completely different from that for high $T^{-1}$ values. The mean of the $\ln T$ values for this case was $\langle Y\rangle=2.297$ and the variance $\sigma_{Y}^{2}=3.727$. Flow simulation gave a value $T_{\text {eff }}=15.63$, higher than the geometric mean, $T_{\mathrm{G}}=9.94$ ( $57 \%$ increase) .

\subsection{Field number 4}

Another possibility consists of automating the method of connecting the high $T$ values. For that purpose a new program, GROWCON, was developed. A description of the algorithm and several examples can be seen in Girardi et al. (1994). A brief summary of the basic steps to generate a heterogeneous $T$ field using GROWCON follows.

The starting point is an already existing transmissivity field, generated using any random field simulator (turning bands, sequential simulation, boolean,...). The program identifies a number of clusters of high $T$ values and tries to connect them by relocating blocks of high $T$. That is, high point $T$ values are rearranged by exchanging positions with medium or low $T$ values (Fig. 10). This can be done by elongating high $T$ clusters, according to several rules, in the direction of their closest neighbours until connection is established. A realization of an original field and the one obtained after GROWCON can be seen in Fig. 11. Fig. 11(b) shows clearly how high $T$ values (in black) are now connected in a very different way from low ones (in white). It also reflects the invariance by a $90^{\circ}$ rotation. 


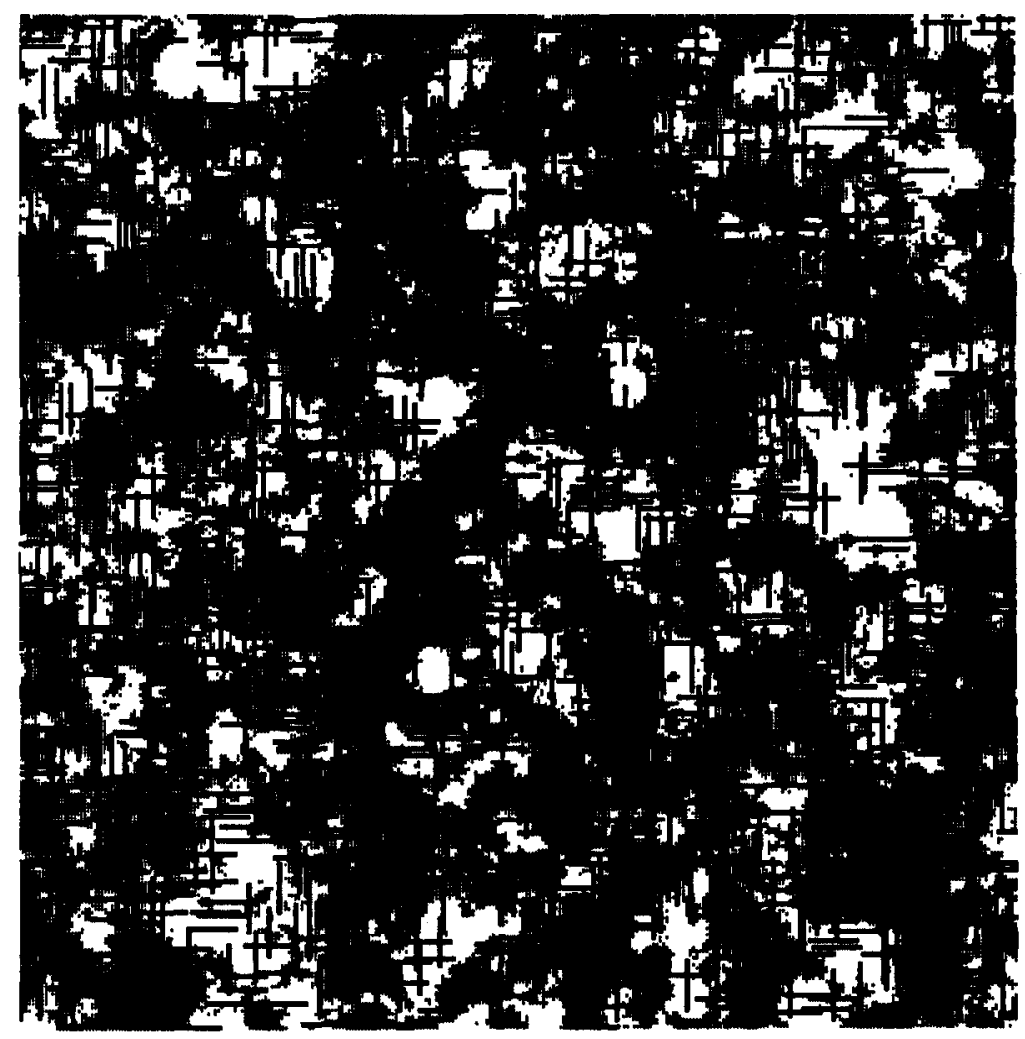

Fig. 9. Grey plot for synthetic field number 3.

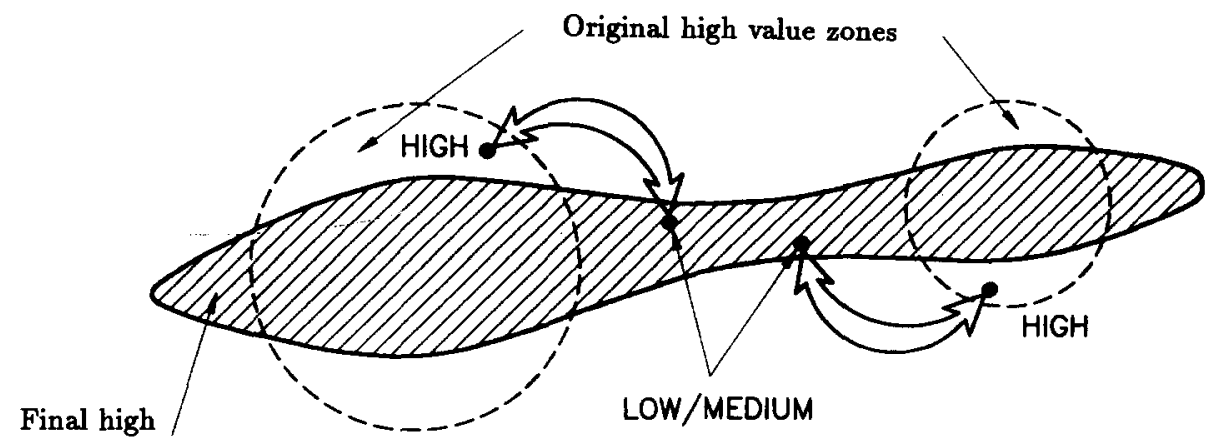

value zone

Fig. 10. The change in connectivity patterns as performed by GROWCON. 
It is important to note that such a procedure does not change the shape of the histogram for the $\ln T$ field. The variogram, however, changes. Moreover, we keep the normality of the univariate distribution of $T$ values, but we do not keep multinormality. Thus, the first two statistical moments (expected value and variogram) are not enough to characterize the random function fully. In order to show the changes in the variogram, we plot in Figs. 12(a) and (b) the original (nested) variogram and the one obtained after GROWCON in the $X$-direction. Actually, the change in variogram is not relevant for our purposes. We could generate a multinormal field with the variogram of Fig. 12(b) and it would not reproduce the connectivity patterns of Fig. 11(b). The important issue is that, having departed from normality, the variogram does not suffice for characterizing spatial variability.

We generate by these means a number of synthetic fields with constant zero mean $(\langle Y\rangle=0.0)$ and different $\sigma_{Y}^{2}$ values. Carrying out flow simulations in each one of them, we can compute $T_{\text {eff }}$. Results are summarized in Table 1, where it is shown that $T_{\text {eff }} / T_{\mathrm{G}}$ is consistently larger than 1.0 (as predicted by theory for the multilog-normal case). It is also shown that this ratio increases more than linearly with the degree of heterogeneity $\left(\sigma_{Y}^{2}\right)$.

\section{Summary and conclusions}

Heterogeneity is one of the most difficult aspects in modelling groundwater flow and solute transport, both in porous and fractured media. When it is not taken into account explicitly, several inconsistencies arise. One of the most striking results is the appearance of scale effects in transmissivity. That is, effective transmissivity often increases with increasing scale of observation. These effects have appeared a number of times in the recent groundwater literature. Traditional stochastic approaches, where transmissivity is treated as a multilog-normal stationary random variable that can be fully characterized with its mean and its correlation structure, are not capable of explaining such effects.

In this work, we intended to give some insight into this problem. We have compiled a number of different works that show scale effects in $T$, and we have provided a geological justification for the non-log-normality of the multivariate statistics in real fields. We generate a number of synthetic $T$ fields with different types of correlation structures, keeping every time the log-normality of the monovariate statistics, but not the multilog-normality. We carried out flow simulations, under simple boundary conditions, for each field and computed effective transmissivities in every case. We found that departures from the multilog-normality assumption can lead to $T_{\text {eff }}$ values different from the geometric mean of the point values. In particular, we observed that structures favouring increased connectivity between high $T$ values consistently result in effective values higher than $T_{\mathrm{G}}$.

In summary, empirical observations suggest a quite widespread scale dependence of $T$. That is, effective large-scale $T$ often exceeds $T_{\mathrm{G}}$, contrary to what conventional multilog-normal stochastic hydrology predicts. Numerical experiments demonstrate that one possible explanation for this contradiction is the non-multinormality of 

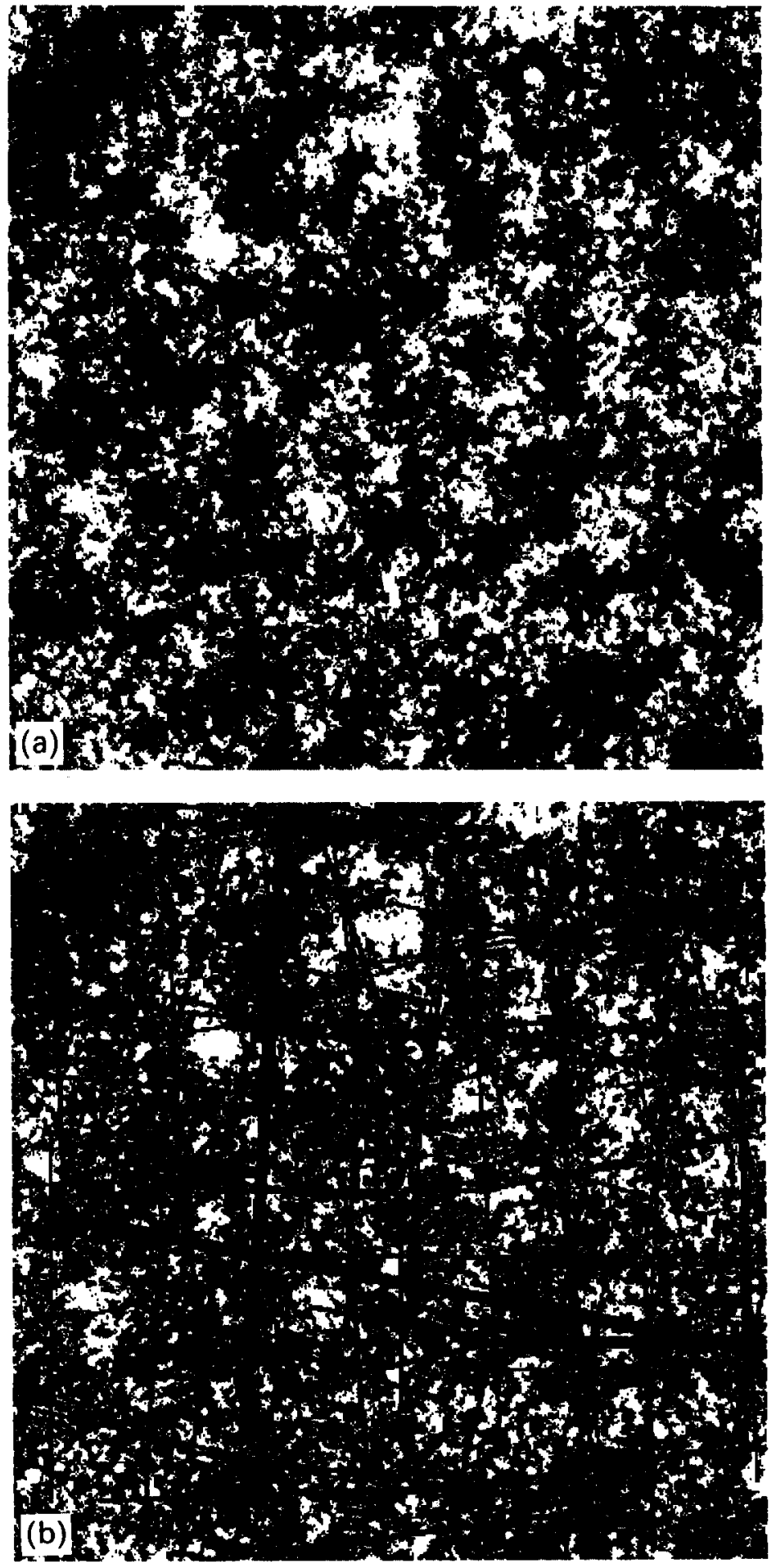

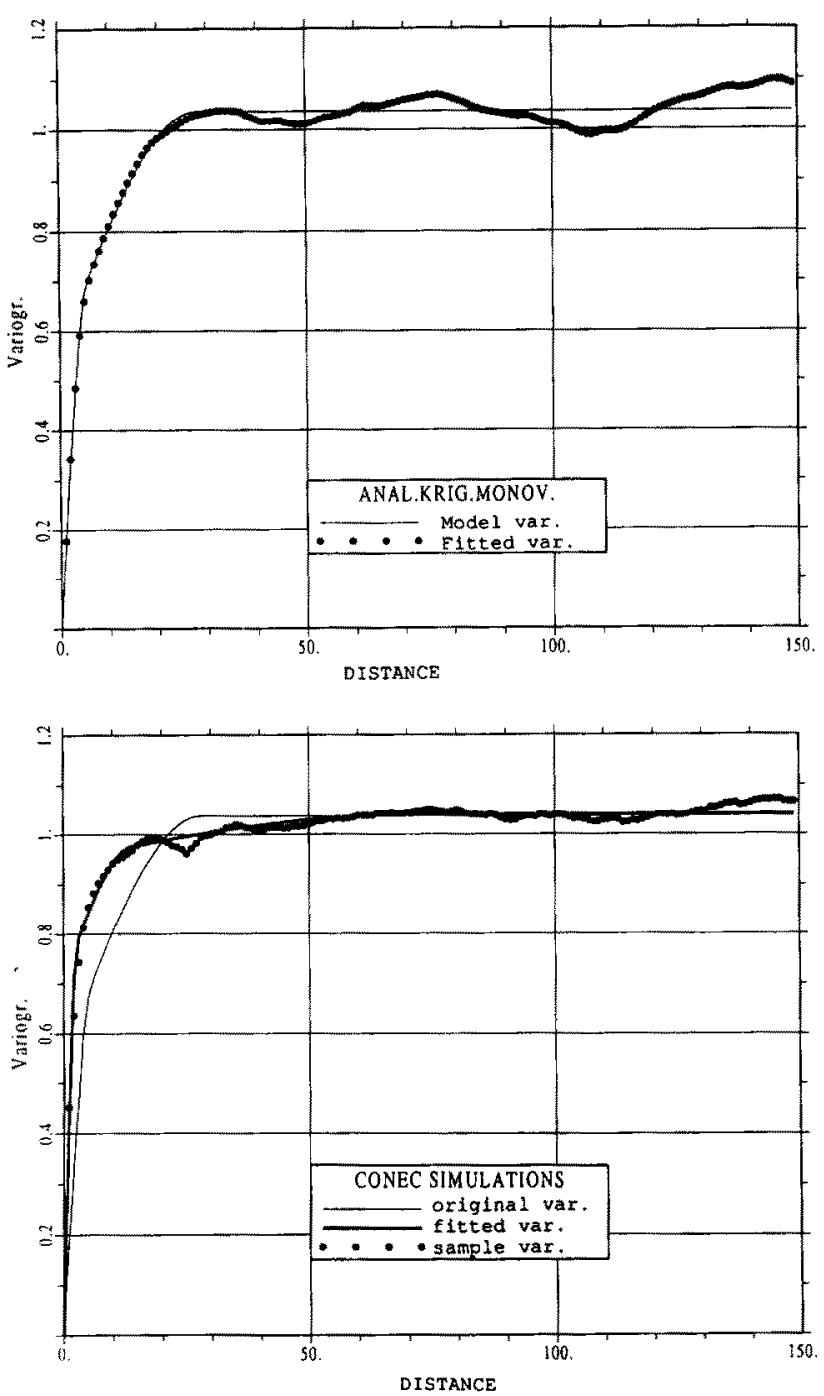

Fig. 12. Sample variogram for the original field plus fitted variogram (a). Variogram for the transformed field (raw data and best fit are represented) (b).

Fig. 11. Input (a) and output (b) fields of GROWCON. Original field generated with GCOSIM3D with a nested variogram. 
Table 1

Results of computed $T_{\text {eff }}$

\begin{tabular}{lll}
\hline Field & $\sigma_{Y}^{2}$ & $T_{\text {eff }} / T_{\mathrm{G}}$ \\
\hline 4.1 & 1.0 & 1.11 \\
4.2 & 2.1 & 1.25 \\
4.3 & 4.1 & 1.52 \\
4.4 & 9.3 & 2.57 \\
\hline
\end{tabular}

$\log -T$ and, specifically, the increased connectivity of high $T$ zones with respect to low $T$ zones. This conjecture is, in generic terms, supported by geology. Therefore, we conclude that multinormal models for $\log -T$ provide a poor representation of reality.

\section{Acknowledgements}

This work was funded by ENRESA (Spanish nuclear waste disposal company) and the EEC through grant RADWAS F12W-CT91-0080 and by CICYT through grant PB-1015. Numerical work was performed on the CRAY-YMP-2E supercomputer at the Centre de Supercomputació de Catalunya (CESCA).

\section{References}

Ababou R. and Wood, E.F., 1990. Comment on "Effective groundwater model parameter values. Influence of spatial variability of hydraulic conductivity, leakance, and recharge by J.J. Gómez-Hernández and S.M. Gorelick", Water Resour. Res., 26(8): 1843-1846.

Bradbury, K.R. and Muldoon, M.A., 1990. Hydraulic conductivity determinations in unlithified glacial and fluvial materials. In: D.M. Nielsen and I. Johnson (Editors), Ground Water and Vadose Zone Monitoring, ASTM STP 1053. American Society for Testing and Materials, Philadelphia, pp. 138-151.

Bourke, P.J., 1987. Channelling of flow through fractures in rock. In GEOVAL 1987. Stockholm, 7-9 April. Swedish Nuclear Power Inspectorate (SKI), Stockholm, Vol. 1. pp. 167-177.

Bredehoeft, J.D., Neuzil, C.E. and Milly, P.C.D., 1983. Regional flow in the Dakota aquifer: a study of the role of confining layers. U.S., Geol. Surv., Water Supply Pap. 2237.

Cacas, M.C., Ledoux, E., de Marsily, G., Tillie, B., Barbreau, A., Durand, E., Feuga, B. and Peaudecerf, P., 1990. Modeling fracture flow with a stochastic discrete fracture network: Calibration and validation. 1 . The flow model. Water Resour. Res., 26: 479-489.

Carrera, J., 1993. An overview of uncertainties in modelling groundwater solute transport. J. Contam. Hydrol., 13 23-48.

Carrera, J. and Heredia, J., 1988. Inverse modeling of the Chalk River Block, HYDROCOIN Level 2/Case 3 and Level 3/Case 5A. NAGRA TB 88-14, 117 pp. 1988.

Carrera, J., Heredia, J., Vomvoris, S. and Hufschmied, P., 1990. Modeling of flow on a small fractured monzonitic gneiss block. In S.P. Neuman and I. Neretnicks (Editors), Hydrogeology of Low Permeability Environments, Hydrology Selected Papers, Heinz Heise, Hannover, Vol. 2. pp. 115-169.

Clauser, C., 1992. Permeability of crystalline rocks. EOS, 73: 233-238.

Dagan, G., 1982. Stochastic modeling of groundwater flow by unconditional and conditional probabilities, 1. Conditional simulation and the direct problem. Water Resour. Res., 18: 813-833. 
Dagan, G., 1986. Statistical theory of groundwater flow and transport: Pore to laboratory, laboratory to formation, and formation to regional scale. Water Resour. Res., 22: 120S-134S.

Dagan, G., 1993. Higher-order correction of effective permeability of heterogeneous isotropic formations of lognormal conductivity distribution. Transp. Porous Media, 12: 279-290.

Davis, S.N., 1969. Porosity and permeability of natural materials. In: R.J.M. De Wiest (Editor), Flow Through Porous Media. Academic, New York, pp. 54-89.

Desbarats, A.J., 1987. Numerical estimation of effective permeability in sand-shale formations. Water Resour. Res., 23: 273-286.

Desbarats, A.J., 1992. Spatial averaging of hydraulic conductivity in three-dimensional heterogeneous porous media. Math. Geol., 24: 249-267.

Fogg. G.E., 1990. Architecture and interconnectedness of geologic media: Role of the low-permeability facies in flow and transport. In: S.P. Neumann and I. Neretnicks (Editors), Hydrogeology of Low Permeability Environments. Hydrology Selected Papers. Heinz Heise, Hannover, Vol. 2. pp. 19-40.

Follin, S., 1992. Numerical calculations of heterogeneity of groundwater flow. Ph.D. Dissertation, Department of Land and Water Resources, Royal Institute of Technology, Stockholm.

Gelhar, L.W. and Axness, C.L., 1983. Three-dimensional stochastic analysis of macrodispersion in aquifers. Water Resour. Res., 19: 161-180.

Girardi, J.P., Sánchez-Vila, X. and Carrera, J., 1994. An algorithm for increasing connectivity of high values in heterogeneous formations. Universitat Politècnica de Catalunya, Internal Rep., UPC, Barcelona.

Gómez-Hernández, J.J., 1991. A stochastic approach to the simulation of conductivity fields conditioned upon data measured at a smaller scale. Ph.D. Dissertation, Department of Applied Sciences, Stanford University, California.

Gómez-Hernández, J.J. and Gorelick, S.M., 1989. Effective groundwater model parameter values: influence of spatial variability of hydraulic conductivity, leakance and recharge. Water Resour. Res., 25: 405-419.

Gómez-Hernández, J.J. and Journel, A.G., 1993. Joint sequential simulation of multigaussian fields. In A. Soares (Editor), Gcostatistics Tróia '92, Vol. 1. Kluwer, Dordrecht, pp. 85-94.

Gómez-Hernández, J.J. and Srivastava, R.M., 1990. ISIM3D: An ANSI-C three dimensional multiple indicator conditional simulation program. Comput. Geosci., 16: 395-440.

Guerin, F. and Billaux, D., 1993. On the relationship between connectivity and the continuum approximation in the fracture flow and transport modeling. In: S. Banks and D. Banks (Editors), Memoires of the XXIVth Congress of IAH, Oslo, Geological Survey of Norway, Trondheim, 28-2 July 1993, Vol. 1. pp. 215-224.

Gutjahr, A.L., Felhar, L.W., Bakr, A.A. and MacMillan, J.R., 1978. Stochastic analysis of spatial variability in subsurface flow. 2: Evaluation and application. Water Resour. Res. 14: 953-960.

Journel, A.G., Deutsch, C. and Desbarats, A.J., 1986. Power averaging for block effective permeability. SPE 15128, presented at the 56th California Regional Meeting of the Society of Petroleum Engineers, Oakland, CA, (unpublished).

Kitanidis, P.K., 1990. Effective hydraulic conductivity for gradually varying flow. Water Resour. Res., 26: $1197-1208$.

Lallemand-Barres, P. and Peaudecerf, P., 1978. Recherche des relations entre la valeur de la dispersivite macroscopique d'un milieu aquifere, ses autres caracteristiques et les conditions de mesure. Etude Bibliographique, Bull. Bureau de Recherches Géologiques et Minières, section III, no. 4, pp. 277-284.

Landau, L.D. and Lifshitz, E.M., 1960. Electrodynamics of Continuous Media. Pergamon, Oxford.

Law, J., 1944. A statistical approach to the interstitial heterogeneity of sand reservoirs. Trans. Am. Inst. Mech. Eng., 155: 202-222.

Loaiciga, H.A., Leipnik, R.B., Mariño, M.A. and Hudak, P.F., 1993. Stochastic groundwater flow analysis in the presence of trends in heterogeneous hydraulic conductivity fields. Math. Geol., 25: 161-176.

Matheron, G., 1976. Elements pour une Theorie des Milieux Poreux. Maisson et Cie, Paris.

Naff, R.L., 1991. Radial flow in heterogeneous porous media: an analysis of specific discharge. Water Resour. Res., 27: 307-316.

Neretnieks, I., 1987. Channeling effects in flow and transport in fractured rocks. Some recent observations and models. In: GEOVAL 1987, Stockholm, 7-9 April. Swedish Nuclear Power Inspectorate (SKI), Stockholm., Vol. 1. pp. 315-335. 
Neuman, S.P., 1987. Stochastic continuum representation of fracture rock permeability as an alternative to the REV and fracture network Concepts. In: E. Custodio, A. Gurgui and J.P. Lobo Ferreira (Editors), Groundwater flow and Quality Modelling. Reidel, Dordrecht, pp. 331-362.

Neuman, S.P., 1994. Generalized scaling of permeabilities: validation and effect of support scale. Geophys. Res. Lett., 21: 349-352.

Neuman, S.P. and Orr, S., 1993. Prediction of steady state flow in nonuniform geologic media by conditional moments: exact nonlocal formalism, effective conductivities and weak approximation. Water Resour. Res., 29: 341-364.

Neuzil, C.E., 1986. Groundwater flow in low-permeability environments. Water Resour. Res., 22: 11631195.

Paleologos, E.K. and Neuman, S.P., 1995. The effects of prescribed head boundaries on the effective hydraulic conductivity under uniform mean flow. Water Resour. Res., submitted.

Raven, K.G., Smedley, J.A., Sweezey, R.A. and Novakowski, K.S., 1985. Field investigations of small ground water flow system in fractured monzonitic gneiss. In: Mem. 17th Int. Congress of International Association of Hydrologists, Vol. 17. IAH Tucson, AZ, pp. 72-86.

Sánchez-Vila, X., Carrera, J. and Colominas, I., 1992. Directional effects on convergent flow tracer tests. In: H. Hötzl and A. Werner (Editors), Proc. 6th Int. Symp. on Water Tracing. Karlsruhe, 21-26 September 1992. Balkema, Rotterdam, pp. 407-414.

Sánchez-Vila, X., Colominas, I. and Carrera, J., 1993. User's Guide for Program FAITH. Universitat Politècnica de Catalunya, Barcelona.

Schvidler, M.I., 1964. Filtration Flows in Heterogeneous Media (A Statistical Approach). Consultants Bureau, New York.

Smith, L. and Freeze, R.A., 1979. Stochastic analysis of steady-state groundwater flow in bounded domain: two-dimensional simulations. Water Resour. Res., 18: 1543-1559. 